\title{
FORMATION AND CHARACTERISATION OF CHROMATE-FREE CONVERSION LAYERS ON 5556 ALUMINUM ALLOY
}

\author{
${ }^{1}$ Anastasiia KOLESNIKOVA, ${ }^{1}$ Aleksey ABRASHOV, ${ }^{1}$ Nelya GRIGORYAN, ${ }^{1}$ Tigran VAGRAMYAN \\ ${ }^{1}$ MUCTR - D.Mendeleev University of Chemical Technology of Russia, Moscow, Russia, \\ nastya-koleso@mail.ru
}

https://doi.org/10.37904/metal.2021.4173

\begin{abstract}
The processes of applying cerium and titanium, zirconium-containing coatings to 5556 aluminum alloy have been developed. It is established that the developed passivation coatings applied on aluminum alloy parts for corrosion resistance and protective ability are comparable with chromate coatings. It was revealed that, unlike chromate coatings, the developed cerium and titanium, zirconium-containing coatings withstand the thermal shock without degrading of characteristics. It was established that the thickness of cerium-containing coatings is about $300 \mathrm{~nm}$, and that of titanium, zirconium-containing coatings is about $100 \mathrm{~nm}$.
\end{abstract}

Keywords: Corrosion protection, conversion coatings, titanium-containing coatings, zirconium-containing coatings, cerium-containing coatings, surface treatment, chromate-free passivation

\section{INTRODUCTION}

Aluminum alloys are widely used as a structural material in various fields of technology, in industrial and civil construction for the manufacture of building frames, window frames, stairs, in the automotive industry, in shipbuilding, aviation and space technology, in electrical engineering, in nuclear reactor construction, etc. [1]. Due to the presence of a thin natural oxide film on the surface, aluminum and its alloys are sufficiently resistant to corrosion, therefore, in some cases, they are used without special anti-corrosion protection. However, due to its low thickness, the natural film on the surface of aluminum often does not provide reliable protection against corrosion, for example, in a humid industrial atmosphere or in sea water. [1,2].

Protective and decorative electrochemical oxidation (anodizing), paint coatings, as well as complex coatings, consisting of the oxide film and a paint coating applied on top of it, depending on the alloy grade, the structure of the product, its purpose, working conditions and other factors can all be used as corrosion protection. Chemical oxide coatings have lower protective and adhesive properties than the electrochemical ones and thus don't have a wide range practical applications.

Conversion chromate coatings are widely used to create a thin adhesive layer as a base for paint coating on the surface aluminum and its alloys. Chromate adhesive coatings are also preferable when painting products with a complex profile, because, in the case of such products, anodizing is known to cause difficulties and thus requires additional spending and technical tricks [3-6].

Due to the high toxicity of chromating solutions, which include highly toxic hexavalent chromium compounds, and the conversion coatings formed in them, which also contain up to $200 \mathrm{mg} / \mathrm{m}^{2}$ of $\mathrm{Cr}^{6+}$, the legislation of many States significantly restricts or completely prohibits the use of conversion chromate coatings. The problem of replacing the chromating processes has become critical after the adoption of the European Directive 2000/53/EC in 2000 restricting the presence of $\mathrm{Cr}$ (VI) compounds in conversion coatings [7], and in 2002 the amendments to the directive, which completely prohibits from July 2007 the presence of $\mathrm{Cr}(\mathrm{VI})$ in conversion coatings applied in the production of automobiles [8]. Similar directives have come into operation in China since March 1, 2007, and in South Korea since July 1, 2007. In addition, RoHS [9] and WEEE [10] 
prohibit the presence of $\mathrm{Cr}(\mathrm{VI})$ in metallic coatings of electrical and electronic equipment; the use of $\mathrm{Cr}(\mathrm{VI})$ limits the $\mathrm{REACH}$ regulation [11].

In the resent years in the world practice nanoscale particles obtained from hexafluorozirconic and hexafluorotitanic acids are more and more often used as an alternative to chromate layers [12-18]. Currently, world leading companies are actively developing the technologies necessary for production of such surfaces.

Among the alternative corrosion inhibitors of aluminum alloys to chromates, the literature describes salts of rare earth metals, in particular cerium, which is an environmentally friendly and quite effective corrosion inhibitor of metals such as aluminum and zinc [19-23]. In this regard, cerium-containing conversion coatings can become a possible replacement for adhesive chromate conversion coatings.

This work is devoted to the development of the process of applying adhesive protective titanium, zirconiumcontaining and cerium-containing conversion coatings under paintwork on the surface of the 5556 aluminum alloy in order to replace the environmentally hazardous chromating processes.

\section{EXPERIMENTAL MATERIALS}

For the application of conversion coatings, samples of an aluminum alloy AA 5556 widely used in the automotive industry of the size of $3 \times 4 \mathrm{~cm}$ were used. Solutions were prepared of pure and pro analysis grades of chemicals and distilled water.

Developed titanium, zirconium-containing and cerium-containing coatings were compared in characteristics with chromate coatings, for application of which solutions based on $\mathrm{Cr}(\mathrm{VI}): \mathrm{Na}_{2} \mathrm{Cr}_{2} \mathrm{O}_{7} 15 \mathrm{~g} / \mathrm{l}$ were used; $\mathrm{Na}_{2} \mathrm{CO}_{3}$ $60 \mathrm{~g} / \mathrm{l} ; \mathrm{T}=95-100^{\circ} \mathrm{C} ; 20-30$ minutes.

To accelerate the evaluation of the protective ability of conversion coatings, a drop-express method was used using an Akimov solution containing: $\mathrm{CuSO}_{4} \cdot 5 \mathrm{H}_{2} \mathrm{O} 82 \mathrm{~g} / \mathrm{l}, \mathrm{NaCl} 33 \mathrm{~g} / \mathrm{l}, 0.1 \mathrm{~N} \mathrm{HCl} 13 \mathrm{ml} / \mathrm{l}$. The PAA (Akimov's protective ability) of conversion coatings on aluminum or its alloys is estimated by this method as time (in seconds) before the color change at the surface under a drop from gray to black.

The thickness of the coatings was determined by ellipsometric method using the spectroscopic ellipsometer SENreseach 4.0 from SENTECH.

The composition of the surface layers was studied using X-ray photoelectron spectroscopy (Omicron, Taunusstein, Germany) (XPS). The panoramic spectra were also recorded after argon-ion etching of the coating in different depths. Thus, the composition of the coating at different distances from the substrate was determined. The pressure of the inert gas in the working chamber was maintained at this level, so that the ion energy and the ion current rate, and consequently, the etching rate, were constant. When analyzing the obtained spectra, it was considered that the analyzing beam penetrates the material to the depth of $5 \mathrm{~nm}$, i.e., the resulting spectra correspond to a layer of material $5 \mathrm{~nm}$ thick.

The adhesion of the coatings was determined by the normal detachment method using the PosiTest AT digital adhesion meter. The method is based on measuring the minimum breaking tension required to separate or rupture the coating in a direction perpendicular to the substrate surface.

Corrosion tests were carried out in a salt fog chamber Ascott S450iP in accordance with the international standard ASTM B117.

\section{EXPERIMENTAL}

According to the literature, the solutions for the formation of titan-zirconium-containing compounds contain hexafluorotitanic and hexafluorozirconic acids as their primary components. Taking into account the processability, safety, availability in the present work, cerium nitrogen salt $\mathrm{Ce}\left(\mathrm{NO}_{3}\right)_{3} \cdot 6 \mathrm{H}_{2} \mathrm{O}$ was chosen as the main component of the conversion solution. 


\subsection{Determination of the titanium, zirconium-containing coatings depositing process parameters}

Acid concentration ranges, which allowed the formation of continuous coatings on the aluminum alloy surface with maximum protective capability have been determined. It was revealed that concentration of $\mathrm{H}_{2} \mathrm{TiF}_{6}$ in the solution should be in the interval of $1.2-6 \mathrm{~g} / \mathrm{L}$, and in the interval of $0.8-1.6 \mathrm{~g} / \mathrm{L}$ for $\mathrm{H}_{2} \mathrm{ZrF}_{6}$ in which the protective ability is at its highest (60-69 s).

Studies made it clear that allowable pH values of solution are present between 4.0 and 5.0 units. Outside this range, coatings are either not generated at all $(\mathrm{pH} \leq 4.0)$, or they are nonuniform and broken $(\mathrm{pH} \geq 5)$.

As can be expected, the protective ability of the coatings depends of the duration of their formation: Akimov protective capability rises during the first 60 seconds and then stabilizes. These is constant is consistent with the results of ellipsometric research. The coating thickness grows over the first $60 \mathrm{~s}$, then stabilizes at $100 \mathrm{~nm}$.

Studied is a solution temperature influence on properties of coatings. It is found out that solution heating up to $40^{\circ} \mathrm{C}$ doesn't results in essential changes of outward appearance and defense capability of coatings, while at higher temperatures $\left(>40^{\circ} \mathrm{C}\right)$ their defense capability has been reduced. That's why an interval of $18-25^{\circ} \mathrm{C}$ has been chosen as a working range, and it was noted that the solution heating up to $40{ }^{\circ} \mathrm{C}$ (in a summertime, for example) is admissible.

In the process of research, the main patterns of the formation of coatings were revealed. Optimization of the composition of the solution and process parameters was carried out. The physicochemical properties of the coatings were investigated with the aim of their application as a substitute for chromate coatings.

Coatings with the best physical and chemical characteristics are formed in a solution with $\mathrm{pH}=4.0-5.0$ at room temperature in 2 minutes of the process.

The chemical composition of the coatings was investigated with the help of X-ray photoelectron spectroscopy. The survey spectra of the coatings indicate the presence of titanium, zirconium, aluminum and oxygen in the coating. Aluminum is present in the coating in the form of $\mathrm{Al}_{2} \mathrm{O}_{3}$ oxide. Zirconium and titanium are present in the coating in the form of $\mathrm{ZrO}_{2}$ and $\mathrm{TiO}_{2}$ oxides [24].

\subsection{Determination of the cerium-containing coatings depositing process parameters}

The dependence of the protective ability of the formed conversion coatings on the duration of treatment in the test solution $\left(10 \mathrm{~g} / \mathrm{l} \mathrm{Ce}\left(\mathrm{NO}_{3}\right)_{3} \cdot 6 \mathrm{H}_{2} \mathrm{O}, \mathrm{pH}=3.0\right)$ was studied.

It was revealed that coating formation is completed under these conditions by the 20th minute of the process. The protective ability of the coatings is stabilized (60 s), and the coating thickness reaches $250 \mathrm{~nm}$. It should be noted that the thickness of chromate coatings is usually $500-1000 \mathrm{~nm}$, and their protective ability according to the Akimov method is $80-100 \mathrm{~s}$.

The coating with the maximum protective ability $(60-70 \mathrm{~s})$ is formed in the range of cerium nitrate concentrations of $6-16 \mathrm{~g} / \mathrm{l}$. When the salt concentration is more than $16 \mathrm{~g} / \mathrm{l}$, the protective ability (PAA) of coatings decreases from 61 to $47 \mathrm{~s}$. In the optimal range of salt concentration, the coating thickness reaches $250 \mathrm{~nm}$, and when the salt concentration is higher than $16 \mathrm{~g} / \mathrm{l}$, the coating thickness is significantly reduced (up to $193 \mathrm{~nm}$ ), which leads to a deterioration of the protective characteristics.

To improve the protective characteristics of the coating and reduce the duration of its formation, an oxidant $\mathrm{H}_{2} \mathrm{O}_{2}$ was introduced into the solution, taking into account the information in the literature. The concentration range of the solution components was determined, in which coatings with the maximum protective ability according to Akimov (up to $80 \mathrm{~s}$ ) were formed. In addition, it should be noted that the introduction of $30-40 \mathrm{ml} / \mathrm{I}$ of hydrogen peroxide into the solution promoted the formation of coatings that were more uniform in appearance. 
Figure 1 shows that, in the presence of hydrogen peroxide in the solution, the thickness of the forming coatings increases to $320 \mathrm{~nm}$, and the duration of the process is reduced to $10 \mathrm{~min}$.

The experiments described above were carried out at a working solution temperature of $18-25^{\circ} \mathrm{C}$. It was found that heating the solution to $40^{\circ} \mathrm{C}$ practically does not affect the properties of coatings, further heating is undesirable, since it leads to a certain decrease in the thickness and protective ability of coatings. Thus, the solution can be heated up to $30^{\circ} \mathrm{C}$ in the summer.
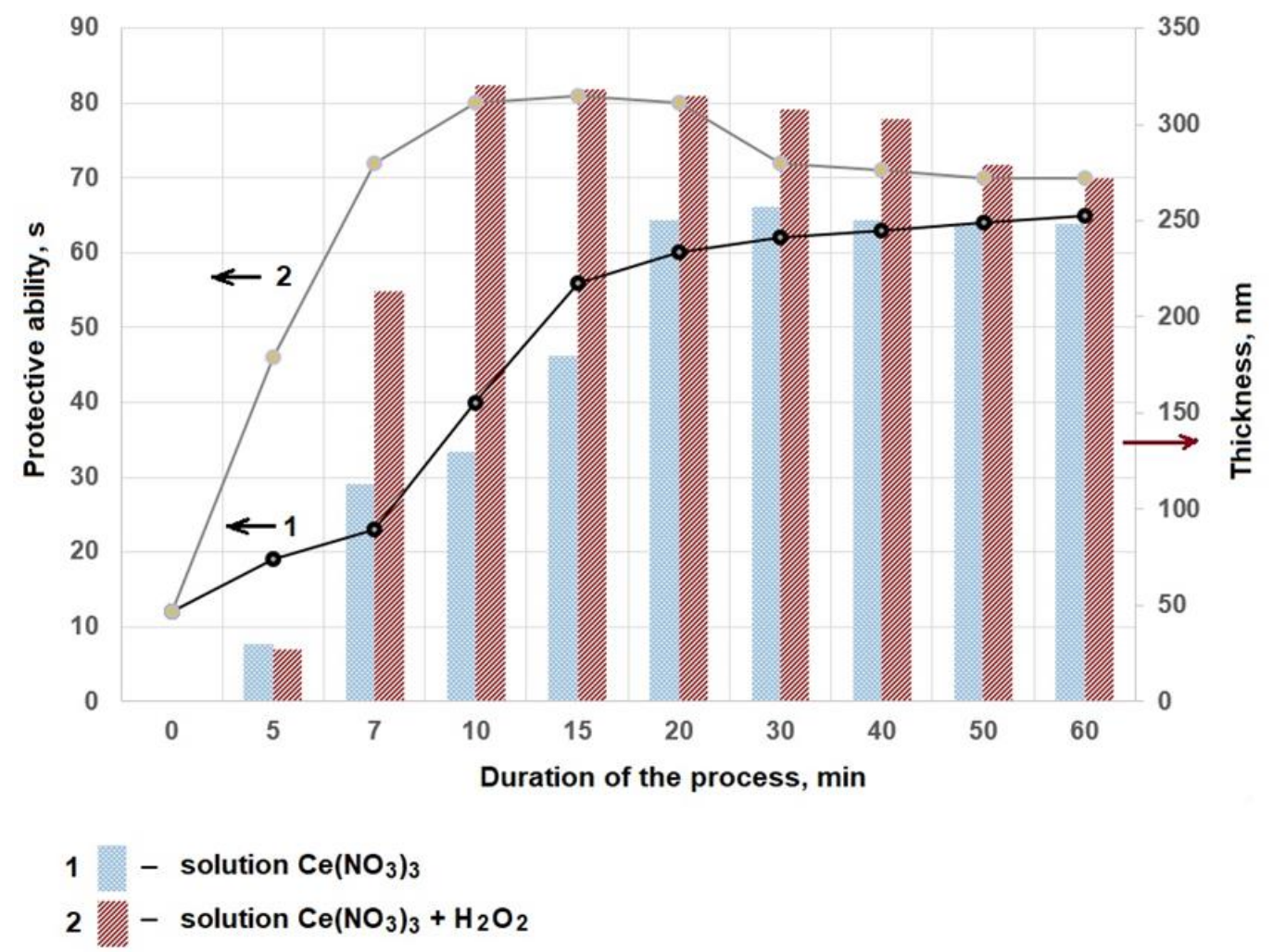

Figure 1 Dependence of the protective ability and thickness of the coatings on the concentration of $\mathrm{Ce}\left(\mathrm{NO}_{3}\right)_{3} \cdot 6 \mathrm{H}_{2} \mathrm{O}$ and $\mathrm{H}_{2} \mathrm{O}_{2}$

The study of the effect of the acidity of the solution on the protective ability of coatings showed that the acceptable $\mathrm{pH}$ values are in the range of 1.5-3.5, and the optimal values are in the range of $2-3 \mathrm{pH}$ units. When the $\mathrm{pH}$ of the solution rises to $\mathrm{pH} \geq 4$, a precipitate of slightly soluble $\mathrm{Ce}^{4+}$ compounds precipitates in the solution.

The survey XPS spectra of the coating formed in the working solution $\mathrm{Ce} / \mathrm{H}_{2} \mathrm{O}_{2}$ indicate the presence of $40.67 \%$ oxygen, $4.68 \%$ cerium, $13.82 \%$ aluminum, $39.02 \%$ carbon in the coating. From the individual spectra of cerium and aluminum, it can be seen that cerium is present in the coating in the three - and four-valent state, and aluminum in the trivalent state. The presence of a carbon peak in the spectrum is explained by the deposition of diffusion oil vapor in the pre-chamber of the spectrometer [23].

\subsection{Tests of the coatings}

Corrosion tests (ASTM B117) in a salt-spray chamber of 5556 aluminum alloy samples with an adhesive titanium, zirconium-containing and cerium-containing coatings, painted with polyester powder paint (Ecocolor PE RAL 9016/P), were carried out. Tests have shown that the developed titanium, zirconium-containing and cerium-containing coatings in terms of protective ability satisfy the requirements for adhesive layers under the paintwork, since the width of corrosion penetration from the place of incision in these cases does not exceed $2 \mathrm{~mm}$ after 750 hours of testing (Figure 2). 
Due to the fact that water-soluble paints are often used in modern painting technologies, the adhesive layers under the paintwork must be moisture resistant. The moisture resistance of the coatings was evaluated by reducing the protective ability after ten minutes of exposure in water. It was found that the protective ability of samples with a titanium, zirconium-containing and cerium-containing coatings practically does not change after moisture resistance tests, which means that the coatings remain moisture resistant.

The strength of paint adhesion for coatings on aluminum alloy with and without various adhesion sub-layers was determined by the detachment method (table 1). The measurements were carried out before and after corrosion tests.

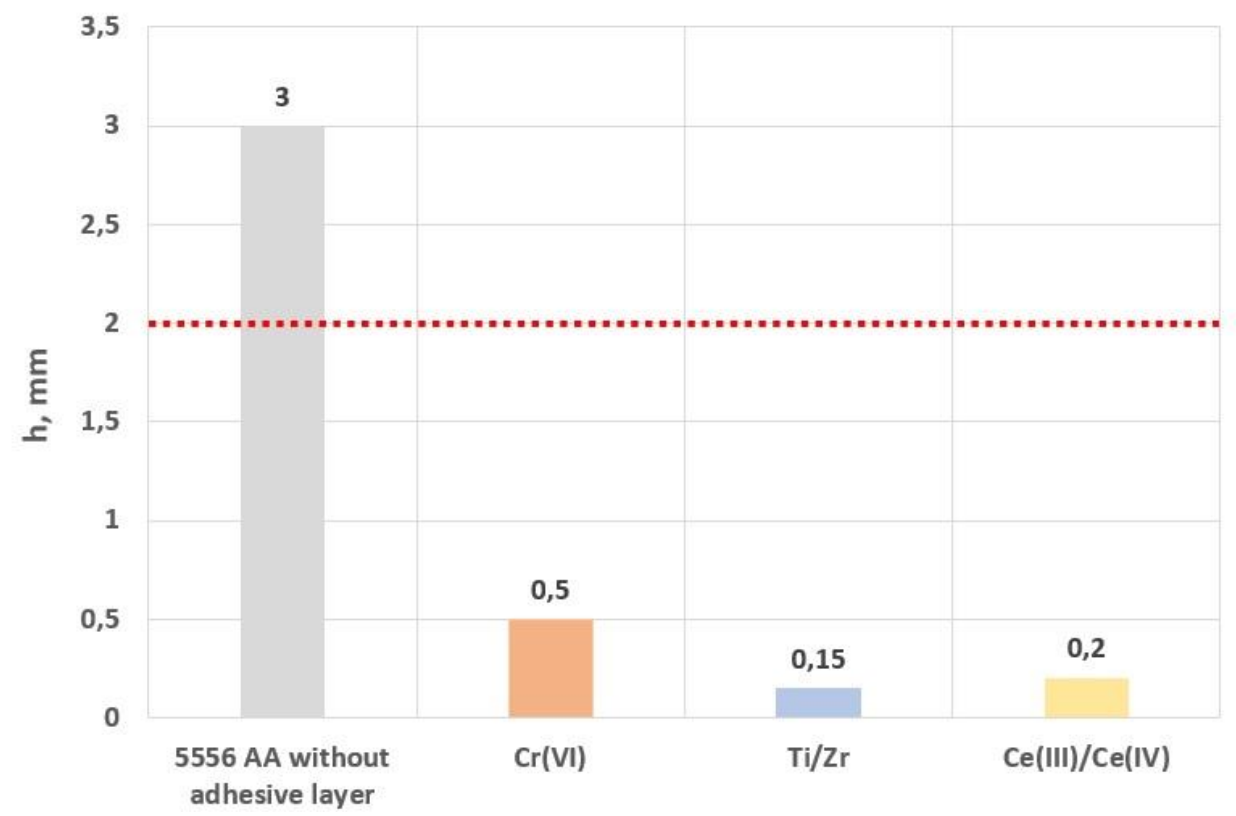

Figure 2 Results of corrosion tests (ASTM B117) of samples with an adhesive coating painted with polyester powder paint; $\mathrm{h}$ - width of corrosion penetration from the place of incision

Table 1 The results of tests for the adhesion strength of coatings were determined by the method of normal detachment using the PosiTest AT digital adhesion meter.

\begin{tabular}{|c|c|c|c|}
\hline \multirow{2}{*}{} & \multicolumn{2}{|c|}{ Adhesion strength, MPa } & Adhesion change, \\
$\%$ & Aefore corrosion tests & After corrosion tests (750 h) & 6,5 \\
\cline { 2 - 4 } & 2,32 & 2,17 & 13,0 \\
\hline $\mathrm{Ti} / \mathrm{Zr}$ & 2,38 & 2,07 & 13,8 \\
\hline $\mathrm{Ce}(\mathrm{III}) / \mathrm{Ce}(\mathrm{IV})$ & 2,25 & 1,94 & 23,4 \\
\hline $\mathrm{Cr}(\mathrm{VI})$ & 1,97 & 1,51 & \\
\hline $\mathrm{AA} 5556$ & & & \\
\hline
\end{tabular}

Tests showed that the adhesion properties of the developed coatings formed in titanium, zirconium-containing solution are comparable with chromate analog. In addition, $\mathrm{Ti}, \mathrm{Zr}$-containing coatings have a minimum adhesion loss value of $8.3 \%$ after corrosion tests.

\section{CONCLUSION}

As a result it was shown that the developed titanium, zirconium-containing and cerium-containing coatings on aluminum alloy 5556 in terms of their protective ability and adhesion properties are comparable to chromate coatings and can be an alternative to toxic chromate coatings in the automotive and other industries. 


\section{ACKNOWLEDGEMENTS}

\section{The work was supported by the Mendeleev University of Chemical Technology of Russia. Project Number X-2020-028}

\section{REFERENCES}

[1] GHALI, E. Corrosion Resistance of Aluminum and Magnesium Alloys Understanding, Performance, and Testing. Wiley Series in Corrosion: John Wiley \& Sons Limited, 2010.

[2] PEDEFERRI, P. Corrosion Science and Engineering. Engineering Materials: Springer Nature Switzerland AG, 2018.

[3] ZHAO, J., XIA, L., SEHGAL, A., LU, D. Effects of chromate conversion coatings on corrosion of aluminium alloy 2024-T3. Surface and Coatings Technology. 2001, vol. 140, pp. 51-57.

[4] CAMPESTRINI, P, TERRYN, H, VEREECKEN, J, DE WIT, JHW. Chromate conversion coating on aluminum alloys. Journal of The Electrochemical Society. 2004, vol. 151, pp. B59-B70.

[5] LIU, Y, ARENAS, AM, GARCIA-VERGARA, SG, SKELDON, P, THOMPSON, GE, SHIMIZU, K, HABAZAKI, H. Ageing effects in the growth of chromate conversion coatings on aluminium. Corrosion Science. 2005; vol.47, pp. 145-150.

[6] FRANKEL, GS, MCCREERY, RL. Inhibition of Al alloy corrosion by chromates. The Electrochemical Society interface. 2001, vol.10, pp.34-38.

[7] Directive 2000/53/EC of the Parliament and the Council of Europe on September 18, 2000 "End-of-livevehicles". Official Journal of the European Communities L269. pp. 34-43.

[8] Replacement hexavalent chromium in automotive industry for ELV Directive. // Harris A. Bhatt, technical paper, Sur/Fin. 6/2002.

[9] Directive 2011/65 / EC (RoHS II) of the European Parliament and of the Council of 8 June 2011 on the restriction of the use of certain hazardous substances in electrical and electronic equipment.

[10] Directive 2002/96 / EC of the European Parliament and of the Council of 27 January 2003 on waste electrical and electronic equipment.

[11] Regulation (EC) No 1907/2006 of the European Parliament and of the Council of 18 December 2006 concerning the registration, assessment, authorization and limitation of chemicals (REACH), the establishment of the European Chemicals Agency.

[12] MILOSEV, I.; FRANKEL, G.S. Review-conversion coatings based on zirconium and/or titanium. Journal of The Electrochemical Society. 2018, vol. 165, pp. C127-C144.

[13] ZHU, W, LI, W, MU, S, FU, N, LIAO, Z. Comparative study on Ti/Zr/V and chromate conversion treated aluminum alloys: anti-corrosion performance and epoxy coating adhesion properties. Applied Surface Science. 2017, vol. 405, pp.157-168.

[14] BECKER M. Chromate-free chemical conversion coatings for aluminum alloys. Corrosion Reviews. 2019, vol. 37, no. 4, pp. 321-342.

[15] ABRASHOV, A.A., GRIGORYAN, N.S., VAGRAMYAN, T.A., ZHILENKO, D.YU. Titaniferous protective coatings on aluminum alloys. Non-ferrous Metals. 2016, no. 11, pp. 33-37.

[16] ABRASHOV, A., GRIGORYAN, N., VAGRAMYAN, T., ASNIS, N. On the Mechanism of Formation of Conversion Titanium-Containing Coatings. Coatings. 2020, vol. 10, no 4, pp. 328 (P. 1-11).

[17] AIHUA, YI, WENFANG, LI, JUN, DU, SONGLIN, MU Effects of $\mathrm{Mn}^{2+}$ on the chrome-free colored Ti/Zr-based conversion coating on 6063 aluminum alloy. Surface and Interface Analysis. 2015, vol. 47, pp. 863-870.

[18] ZUO, X, LI, W, MU, S, DU, J, YANG, Y, TANG, P. Investigation of composition and structure for a novel Ti-Zr chemical conversion coating on 6063 aluminum alloy. Progress in Organic Coatings. 2015, vol. 87, pp. 61-68.

[19] TREU, B.L., JOSHI, S., PINC, W.R., Characterization of Localized Surface States of Al 7075-T6 during Deposition of Cerium-Based Conversion Coatings. J. Electrochem. Soc. 2010, vol. 157, no. 4, pp. $282-287$.

[20] CHEN, S., ZHANG, S., REN, X. Cerium-based Chemical Conversion Coating on Aluminum Alloy to Inhibits Corrosion in Chloride Solution. Int. J. Electrochem. Sci. 2015, vol. 10, pp. 9073-9088. 
[21] GOBARA, M., BARAKA, A., AKID, R., ZORAINY, M., Corrosion protection mechanism of $\mathrm{Ce}^{4+/ o r g a n i c}$ inhibitor for AA2024 in 3.5\% NaCl. RSC Advances. 2020, vol. 10, pp. 2227-2240.

[22] DABALA, M., RAMOUS, E., MAGRINI, M. Corrosion resistance of cerium-based chemical conversion coatings on AA5083 aluminium alloy. Mater. Corros. 2004, vol. 55, pp. 381-386.

[23] ABRASHOV, A.A., GRIGORYAN, N.S., VAGRAMYAN, T.A., SIMONOVA, M.A., MIROSHNIKOV, V.S., ARKHIPUSHKIN, I.A. Surface passivation of 5556 aluminum alloy in solutions based on cerium nitrate. International Journal of Corrosion and Scale Inhibition. 2021, vol. 10, no 1, pp. 132-144.

[24] ABRASHOV, A., KOLESNIKOVA, A., GRIGORYAN, N., VAGRAMYAN ,T. Chromate-free chemical conversion coatings on aluminum alloy 5556. In: Conference Proceedings 29 th Anniversary International Conference on Metallurgy and Materials (METAL 2020). Brno: Tanger, 2020, pp. 764-769. 